\title{
Low density alfuzosin hydrochloride floating tablets: in vitro characterization and in vivo gastroretentive MRI tracking in healthy volunteers
}

\author{
Marwa Abd El-Aziz ${ }^{1}$, Soha Ismail11, Mina Ibrahim Tadros²*, Mohamed El-Nabarawi² \\ 1 Department of Pharmaceutics, National Organization for Drug Control and Research, Giza, Egypt \\ 2 Department of Pharmaceutics and Industrial Pharmacy, Faculty of Pharmacy, Cairo University, Cairo, Egypt
}

\begin{abstract}
The current work aimed to develop promising floating sustained release systems for alfuzosin hydrochloride (ALF) utilizing sublimation technique. Gastroretentive tablets were prepared by direct compression and subsequent sublimation of the loaded sublimable agents. Polyethylene oxide WSR N-60K (PEO) or Carbopol 934 (CP) were used as release retarding polymers. Camphor or menthol were used as sublimable agents at concentrations of $3 \%, 6 \%, 9 \%$ or $12 \%$ w/w. FTIR and DSC were performed to check possible drug-excipients incompatibility. The tablets were evaluated for appearance, hardness, friability, density, floating characters, and in-vitro drug release. The drug release percentages after $0.5 \mathrm{~h}\left(\mathrm{Q}_{0.5 \mathrm{~h}}\right)$ and $8 \mathrm{~h}$ $\left(\mathrm{Q}_{8 \mathrm{~h}}\right)$ were estimated. Based on estimation of the desirability values, the best-achieved formula (F1) was morphologically evaluated via SEM. The gastroretentive tracking of the magnetite-loaded F1 tablets was performed via MRI in healthy human volunteers. FT-IR spectra and DSC thermograms confirmed drug-excipients compatibility. PEO- and CP-based systems exhibited acceptable physicochemical characteristics regarding their appearance, hardness and friability. They exhibited low bulk density values $\left(<1 \mathrm{~g} / \mathrm{cm}^{3}\right)$ allowing them to float spontaneously (zero lag times), for at least $8 \mathrm{~h}$. Significantly higher $(p<0.0001) \mathrm{Q}_{0.5 \mathrm{~h}}$ were revealed with CP-based tablets. No significant difference $(p=0.3529)$ was elucidated between $\mathrm{Q}_{8 \mathrm{~h}}$ values of the corresponding CP-based and PEO-based tablets. Following sublimation, SEM micrographs of F1 confirmed the presence of a low bulk density porous matrix. The gastroretentive potential of F1 was suggested for at least $5 \mathrm{~h}$ in healthy human volunteers. F1 is a promising gastroretentive system for ALF.
\end{abstract}

\section{Keywords:}

Alfuzosin hydrochloride, Floating porous tablets, Sustained release, Sublimation, Gastroretentive tracking, Magnetic resonance imaging

\section{INTRODUCTION}

Sublimation phenomenon is the change of the substance state from solid to gas, upon heating at ordinary atmospheric pressure, without passing through the liquid state ${ }^{1}$. It is an endothermic process that requires energy to overcome the attractive forces between molecules allowing their escape into the vapor phase. Sublimation occurs at temperatures and pressures below a substance's triple point ${ }^{2-3}$. There are numerous applications for sublimation such as separation and purification purposes, freeze-drying (lyophilization) of thermolabile substances and preparation of samples for cryo-scanning electron microscopy (SEM) analysis ${ }^{2}$. Furthermore, sublimation has been recently contributed to the great progression in the design of floating gastroretentive drug delivery systems. It was utilized as a buoyancy achieving technique alone $e^{4}$ or in a combination with other approaches ${ }^{5}$. Herein, the developed matrices are heated in an oven to permit vaporization of the incorporated sublimable agents. This result in developing highly porous systems with extremely low bulk

*Corresponding author:

*Mina Ibrahim Tadros mina.tadros@pharma.cu.edu.eg 
density that allows them to float over the gastric fluid for a long period of time. Camphor (a crystalline ketone) and menthol (a monocyclic terpenoid) are the most prominent sublimable agents utilized for this purpose as they easily sublimate at low temperature ${ }^{6}$. It was reported that l-menthol possessed better buoyancy characteristics with regard to floating lag time and total floatation time than camphor ${ }^{7}$.

Alfuzosin $\mathrm{HCl}$ (ALF) is a selective $\mathrm{a}_{1}$ adrenergic-receptor blocker approved by FDA for the symptomatic treatment of benign prostate hyperplasia (BPH). It affects the tone of the prostate smooth muscles via relaxation rather than affecting the prostate size that in order relief BPH accompanied symptoms ${ }^{8}$. ALF possessed a narrow absorption window, a short biological $\mathrm{t}_{1 / 2}(3.8 \mathrm{~h})$ and a low oral bioavailability $(25 \%)$ under fasting conditions. Interestingly, the latter is approximately increased twice under fed conditions. This might be attributed to the avoidance of the first pass metabolism a long with prolonging the gastric residence time allowing for more drug absorption ${ }^{8}$. On the basis of the aforementioned, scientists were prompted to develop gastroretentive systems loaded with ALF such as mucoadhesive floating beads ${ }^{9}$, floating pellets ${ }^{10}$, floating tablets ${ }^{11}$ to improve its oral bioavailability as well as to sustain its rate of drug release.

In a previous study, the authors of the current work developed and optimized low density gastroretentive chitosan sponges ${ }^{12}$. Herein, Polyethylene oxide WSR N-60K (PEO) and Carbopol 934 (CP) were investigated as release retarding polymers. Along with, camphor and 1-menthol were explored to develop low density tablets following the adoption of sublimation technique. The gastroretentive potential of the best achieved tablet was evaluated in healthy human volunteers via Magnetic resonance imaging (MRI). The superiority and safety of the latter technique to the traditional $X$-ray ${ }^{13}$ and $\Upsilon$-scintigraphy ${ }^{14}$ was proved. MRI possesses the merits of the higher resolution along with the prevention of subject exposure to the ionizing radiations ${ }^{15}$.

\section{MATERIALS AND METHODS}

\subsection{Materials}

Alfuzosin Hydrochloride (ALF) was donated as a gift from Eva Pharma Co. (Giza, Egypt). Carbopol 934 (CP) was provided by Pharco Pharmaceutical Co. (Alexandria, Egypt). Polyethylene oxide WSR N-60K (PEO), camphor and ferric oxide (magnetite) were provided by Sigma-Aldrich Chemical Co. (St. Louis, $\mathrm{MO})$. L-menthol and magnesium stearate and talc were acquired from El Nasr Pharmaceutical Co. (Cairo, Egypt). All other chemicals were of pure analytical grade and were used as obtained.

\subsection{Methods}

\subsubsection{Drug-excipients compatibility studies}

The compatibility of pure ALF with PEO, CP, l-menthol, camphor and their physical mixtures with ALF (1:1 w/w ratio) was investigated via FT-IR and DSC studies.

\subsubsection{Fourier Transform Infrared spectroscopy (FT-IR)}

FT-IR spectral analysis was performed to verify the possible chemical interactions between ALF and the investigated polymers and sublimable agents. The samples were mixed with potassium bromide and compressed to prepare thin disks. Then, using a FT-IR spectrophotometer (IR Affinity-1, Shimadzu, Kyoto, Japan), the disks were scanned over the spectral region $4000-400 \mathrm{~cm}^{-1} 16$.

\subsubsection{Differential Scanning Calorimetry (DSC)}

DSC analysis studies of the samples were performed to assess the compatibility, and the degree of drug crystallinity in the physical mixture. Using a differential scanning calorimeter (DSC-60, Shimadzu, Kyoto, Japan), four milligrams samples were heated over a temperature range of $50-400^{\circ} \mathrm{C}$ with $10^{\circ} \mathrm{C} / \mathrm{min}$ rate and under $30 \mathrm{~mL} / \mathrm{min}$ nitrogen purge.

\subsubsection{Development of ALF-loaded floating tablets}

Design-Expert $^{\circledR}$ Ver. 7.0 (Stat-Ease Inc., Minneapolis, Minnesota) was employed to construct a $2^{2} \times 4^{1}$ full factorial design for the investigation of the influence of three independent variables; type of polymer (A), type of sublimable agent (B) and sublimable agent concentration $(\mathrm{C})$ on the physicochemical characteristics of the developed tablets. The investigated responses were tablet hardness, friability, density, floating behavior and drug released percentages after $0.5 \mathrm{~h}\left(\mathrm{Q}_{0.5 \mathrm{~h}}\right)$ and after $8 \mathrm{~h}\left(\mathrm{Q}_{8 \mathrm{~h}}\right)$ as dependent variables. Two polymers and two sublimable agents, each in four concentrations, were used to develop 16 formulae, in triplicates: as shown in Table 1.

ALF-loaded tablets were prepared by the direct compression method ${ }^{6}$. A multi-step mixing process was utilized to assure drug homogeneity within the tablet matrix. The polymers and the sublimable agents were separately pulverized using a glass mortar and pestle. The powdered samples were sieved and mixed with the drug for $10 \mathrm{~min}$ in a glass mortar. The mixtures were further lubricated with talc and magnesium stearate for $3 \mathrm{~min}$. Finally, $150 \mathrm{mg}$ of each mixture was compressed using tablet press machine (Royal artist, Bombay, India) equipped with $10 \mathrm{~mm}$ flat-faced punches. Finally, the 

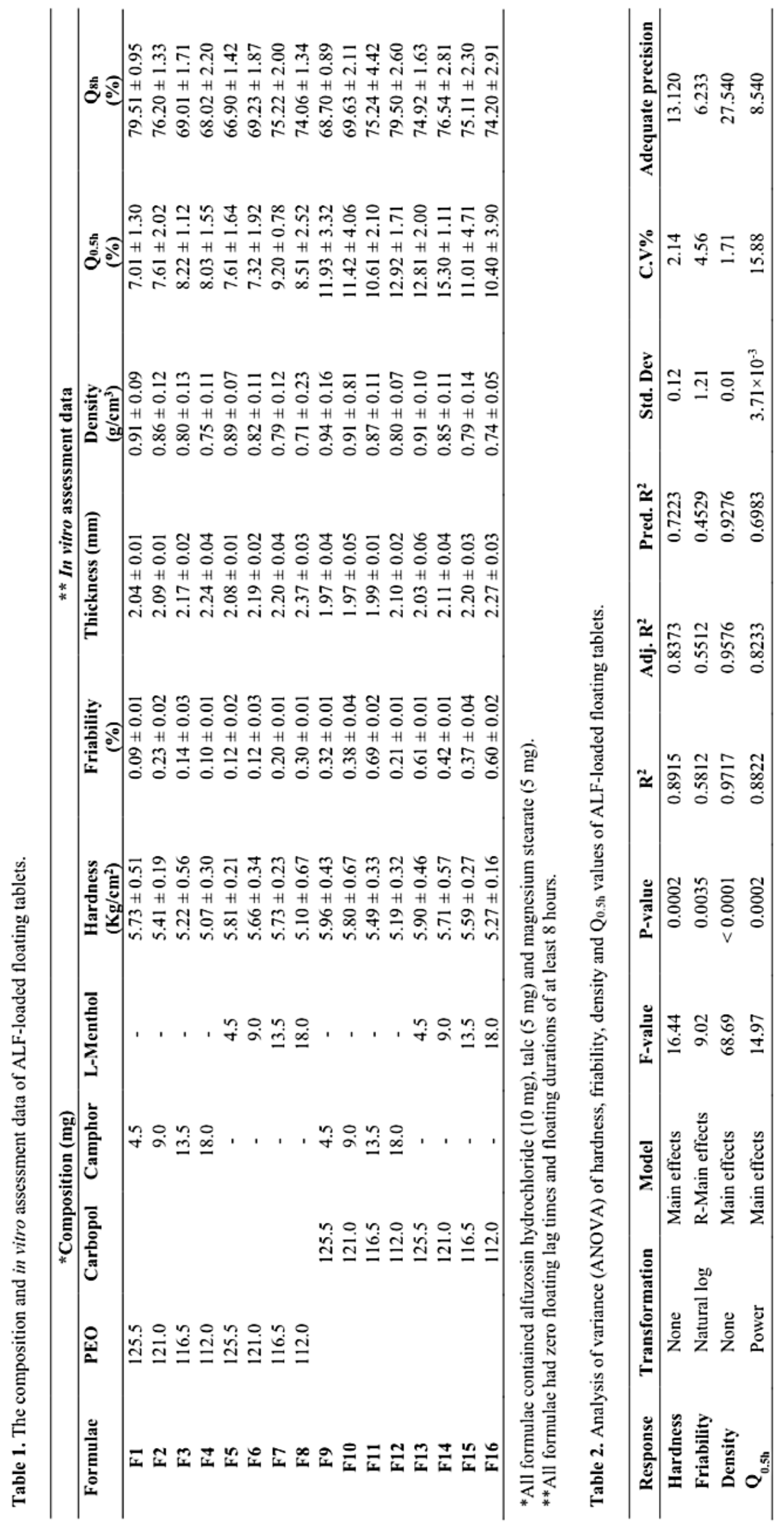
compressed tablets were put in an oven at $50^{\circ} \mathrm{C}$ for $24 \mathrm{~h}$ to allow complete sublimation, as confirmed via the tablet weight testing.

\subsubsection{In-vitro assessment of ALF-loaded tablets}

\subsubsection{Visual inspection}

Tablets were visually inspected, before and after sublimation, for their appearance, physical integrity and possible structural deformity.

\subsubsection{Hardness}

Hardness (crushing strength) of the developed tablets $(n=3)$ was measured after sublimation using hardness tester (Dr. Schleuniger Pharmatron Tablet Tester $8 \mathrm{M}$, Switzerland). The average values were calculated and expressed in $\mathrm{Kg} / \mathrm{cm}^{2}$. Tablets should not be too hard to allow their proper dissolution. By the same token, the tablets should not be too soft to avoid their premature disintegration or breaking during processing and transportation ${ }^{17}$. A hardness value between 5 to $10 \mathrm{~kg} / \mathrm{cm}^{2}$ is convenient and desirable.

\subsubsection{Friability}

Friability of tablets was determined using friabilator test apparatus (ERWEKA, Langen, Germany). According to BP specifications, a sample of tablets corresponding as near as possible to $6.5 \mathrm{~g}$ were exposed to rolling and repeated shocks resulting from their free falls within the apparatus that was rotated at $25 \mathrm{rpm}$ for 4 minutes ${ }^{18}$. Then, they were flicked and re-weighted. The percentage loss in tablet weight expresses its friability and calculated from equation (1).

$$
\% \text { Friability }=\mathrm{W}_{\text {Initial }}-\mathrm{W}_{\text {Final }} / \mathrm{W}_{\text {Initial }} \times 100
$$

\subsubsection{Density}

The thickness (height) and the diameter of the developed tablets $(\mathrm{n}=3)$, after sublimation, were measured using a tablet micrometer (KT-mitutoyo, Mainland, China) and the average values were calculated. Density could be then determined ${ }^{4}$ via equation (2) as follows,

$$
\mathrm{D}=\mathrm{W} /\left[(M / 2)^{2} \times \pi \times \mathrm{h}\right]
$$

where, $\mathrm{W}$ is the tablet weight, $\mathrm{M}$ is the tablet diameter, $\pi$ is the circular constant, and $h$ is the tablet thickness.

\subsubsection{In vitro drug release studies}

A USP Dissolution Apparatus, type II (Hanson Research SR8PLUS, Chatsworth, CA), was employed to perform the in vitro release studies of ALF from the developed tablets, in triplicates, at $37 \pm 0.5^{\circ} \mathrm{C}$. The dissolution medium was $0.1 \mathrm{~N} \mathrm{HCl}(\mathrm{pH} 1.2,500 \mathrm{~mL})$ and the rotation speed of $50 \mathrm{rpm}^{19}$. At specified time intervals $(0.5,1,2,4,6$ and $8 \mathrm{~h})$, a volume of $3 \mathrm{~mL}$ was withdrawn from the medium, filtered through a cellulose acetate membrane $(0.45 \mu \mathrm{m})$. The released percentages of ALF were determined spectrophotometrically at $244 \mathrm{~nm}$ using UV-visible spectrophotometer (SPECORD 210 Plus, Analytikjena, Germany). To keep a constant volume of the dissolution medium, an equal volume of the fresh dissolution medium was replaced at each sampling time. The release profile for each system was obtained via plotting the released percentage of ALF versus time.

Different kinetic models (first order, zero order and Korsmeyer-Peppas) were applied to the drug release data to detect the best fitting model having the highest correlation coefficient, so that the mechanism through which the drug was released could be revealed ${ }^{20}$.

\subsubsection{Assessment of the floating behavior}

The floating behavior of the tablets was observed and recorded, in triplicates, during the conductance of the in vitro drug release studies. The time consumed for tablet emergence on to the surface of the dissolution medium was referred to as the floating lag time whereas, the time during which the tablets remained buoyant was set as the total floatation duration $^{13}$.

\subsubsection{Selection of the best achieved floating tablets}

Four model variables (hardness, friability, density and $\mathrm{Q}_{0.5 \mathrm{~h}}$ ) were implemented to compare different formulae. The analysis of variance (ANOVA) test was used to statistically analyze the obtained data. Based on the numerical optimization and the desirability values, the best achieved formula was promoted for further investigations.

\subsubsection{Characterization of the best achieved floating tablets}

\subsubsection{Structural observation of the best achieved} tablets

Scanning electron microscope (Electron Optical Laboratory, Tokyo, Japan) was used to explore the morphologic and structural nature of the best achieved ALF-loaded tablets. Transverse sections of tablets, before and after sublimation, were treated with gold for 2 minutes under an argon gas vacuum before inspection ${ }^{6}$.

2.2.5.2. Gastroretentive tracking of the best achieved tablets via MRI 


\subsection{Evolution of magnetite-loaded tablets}

Ferric oxide (magnetite) is a well-known MRI negative contrast agent that is utilized for the visualization and estimation of the gastroretentive potential of various dosage forms ${ }^{21}$. Magnetite is considered the preferable one for such purpose due to its safe use in food industry and its low cost. For the obvious detection of the tablet in the stomach without interference either with the ingested food or the intragastric gases, only $15 \mathrm{mg}$ of PEO was replaced with magnetite ${ }^{22}$.

\subsection{Subject admission}

The study protocol was approved by the research ethics committee for clinical studies (Faculty of Pharmacy-Cairo University), approval code (PI 975). Four healthy young male subjects were called to collaborate in the studies after giving an informed written consent. The exclusion criteria were reported in our previous work ${ }^{12}$.

The enrolled volunteers passed several physical examinations as well as laboratory evaluations. They were instructed that taking medications or dietary supplements should be avoided for at least seven days prior to the launching of the studies.

\subsection{Gastric MRI scanning}

All subjects were instructed to fast overnight. Low calorie meals were provided before taking the magnetite-loaded dosage forms. According to Tadros and Fahmy ${ }^{22}$, Coronal T2 and axial T2 MRI scanning were performed prior to ( $0 \mathrm{~h}$; as a reference) and at specified time intervals after the dosage administration (1, 3 and 5 h) using a 1.5 Tesla closed MRI Toshiba equipment (Tokyo, Japan). This would allow the depiction of the dosage form position in the stomach and the determination of its potential to remain there. For obvious gastric visualization, additional $200 \mathrm{~mL}$ of water were provided to the subjects before each MRI scan.

\section{RESULTS AND DISCUSSION}

\subsection{Drug-excipients compatibility studies}

\subsubsection{Fourier Transform Infrared spectroscopy (FT-IR)}

The FT-IR spectra of the polymers (PEO and $\mathrm{CP})$ and their physical mixtures with ALF were depicted in Figure 1A while the FT-IR spectra of the sublimable agents (camphor and 1-menthol) and their physical mixtures with ALF were shown in Figure 1B. As noted and illustrated in our previous work ${ }^{12}$, ALF showed a characteristic N-H vibration peak at $3370 \mathrm{~cm}^{-1}$, aromatic and aliphatic C-H vibration at $2932 \mathrm{~cm}^{-1}$, $\mathrm{C}=\mathrm{O}$ vibrations at 1603,1655 and $1495 \mathrm{~cm}^{-1}$ and $\mathrm{C}-\mathrm{O}$ vibration at $993 \mathrm{~cm}^{-1}$. In addition, the following peaks were revealed in the fingerprint region at $1238 \mathrm{~cm}^{-1}, 871$ $\mathrm{cm}^{-1}$ and $633 \mathrm{~cm}^{-1}$.

PEO possessed characteristic peaks at 3433 $\mathrm{cm}^{-1}$ due to the alcoholic hydroxyl group stretching vibration, at $2869 \mathrm{~cm}^{-1}$ and $1463 \mathrm{~cm}^{-1}$ due to the vibrations of the $\mathrm{C}-\mathrm{H}$ bond and at $1260 \mathrm{~cm}^{-1}$ and $1091 \mathrm{~cm}^{-1}$ due to the asymmetric and symmetric vibrations of C-O-C groups, respectively ${ }^{23-24}$. CP showed a characteristic broad peak at $3000-1940 \mathrm{~cm}^{-1}$ referring to the O-H bond stretching and intra-molecular hydrogen bonding, a peak at $1700 \mathrm{~cm}^{-1}$ due to carbonyl stretching vibrations, a peak at $1250-1200 \mathrm{~cm}^{-1}$ due to bending of C-H of methylene, a prominent peak at $1157 \mathrm{~cm}^{-1}$ indicating C$\mathrm{C}$ vibration ${ }^{25}$, and bands between $1460-1400 \mathrm{~cm}^{-1}$ caused by $\mathrm{C}-\mathrm{O}$ and $\mathrm{O}-\mathrm{H}$ bending vibrations. Camphor showed a characteristic peak at $1739 \mathrm{~cm}^{-1}$ due to the ketonic carbonyl group stretching ${ }^{26}$ while 1-menthol had a characteristic peak at $3293 \mathrm{~cm}^{-1}$ corresponding to the hydroxyl groups stretching vibrations ${ }^{27-28}$.

The permanence of the characteristic peaks of ALF, polymers and sublimable materials in the physical mixtures could confirm their physicochemical compatibility.

\subsubsection{Differential scanning calorimetry (DSC)}

The DSC thermograms of the polymers (PEO and $\mathrm{CP}$ ) and their physical mixtures with ALF were illustrated in Figure 2A, while the DSC thermograms of the sublimable agents (camphor and l-menthol) and their physical mixtures with ALF were portrayed in Figure 2B. As noted and illustrated in our previous work $^{12}$, The DSC thermogram of drug showed an endothermic peak at $236^{\circ} \mathrm{C}$ corresponding to its melting temperature. The sharpness of the peak could confirm the crystalline nature of ALF?

$\mathrm{CP}$ exhibited an endothermic broad peak between $70-330^{\circ} \mathrm{C}$, referring to glass transition and dehydration. It is worth to note the further rise in temperature would cause polymer degradation ${ }^{25}$. PEO possessed a single broad endothermic peak between 65 and $72^{\circ} \mathrm{C}$, referring to its melting temperature and an exothermic peak at $182^{\circ} \mathrm{C}^{29}$.

On the other hand, 1-menthol and camphor absorb the heat for volatilization during heating cycles, they did not show regular melting peaks; L-menthol exhibited a broad endothermic irregular peak with an onset at $182^{\circ} \mathrm{C}$ and an endset at $225^{\circ} \mathrm{C}$ whereas camphor showed an irregular endothermic peak with an onset at $177^{\circ} \mathrm{C}$ and an endset at $216^{\circ} \mathrm{C}$ corresponding to their thermal decomposition ${ }^{30}$.

The persistence of the characteristic ALF peak 


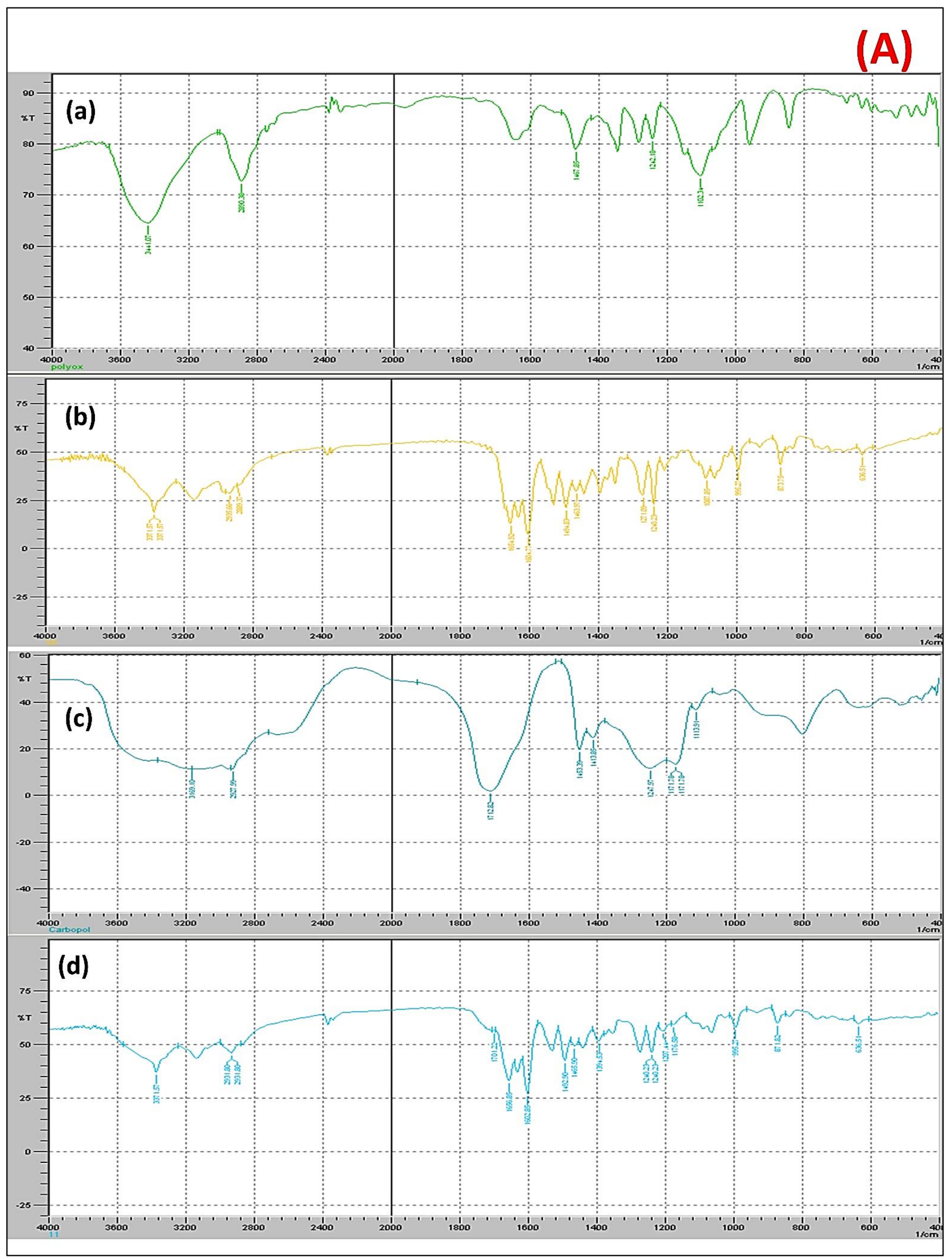

Figure 1A. FT-IR spectra of PEO (a), ALF-PEO physical mixture (b), CP 934 (c), ALF-CP physical mixture (d). 


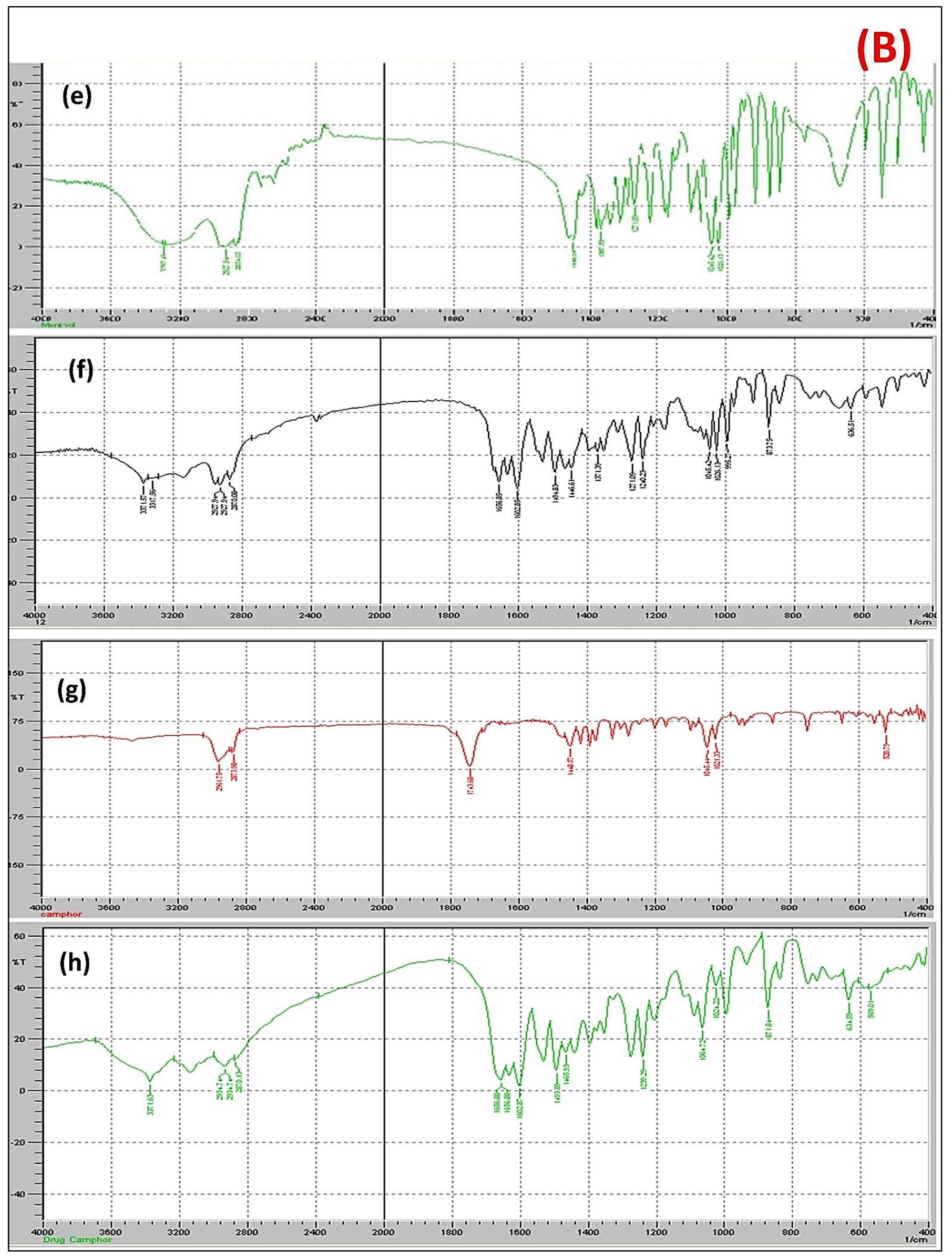

Figure 1B. FT-IR spectra of menthol (e), ALF-menthol physical mixture (f), camphor (g) and ALF-camphor physical mixture (h). 

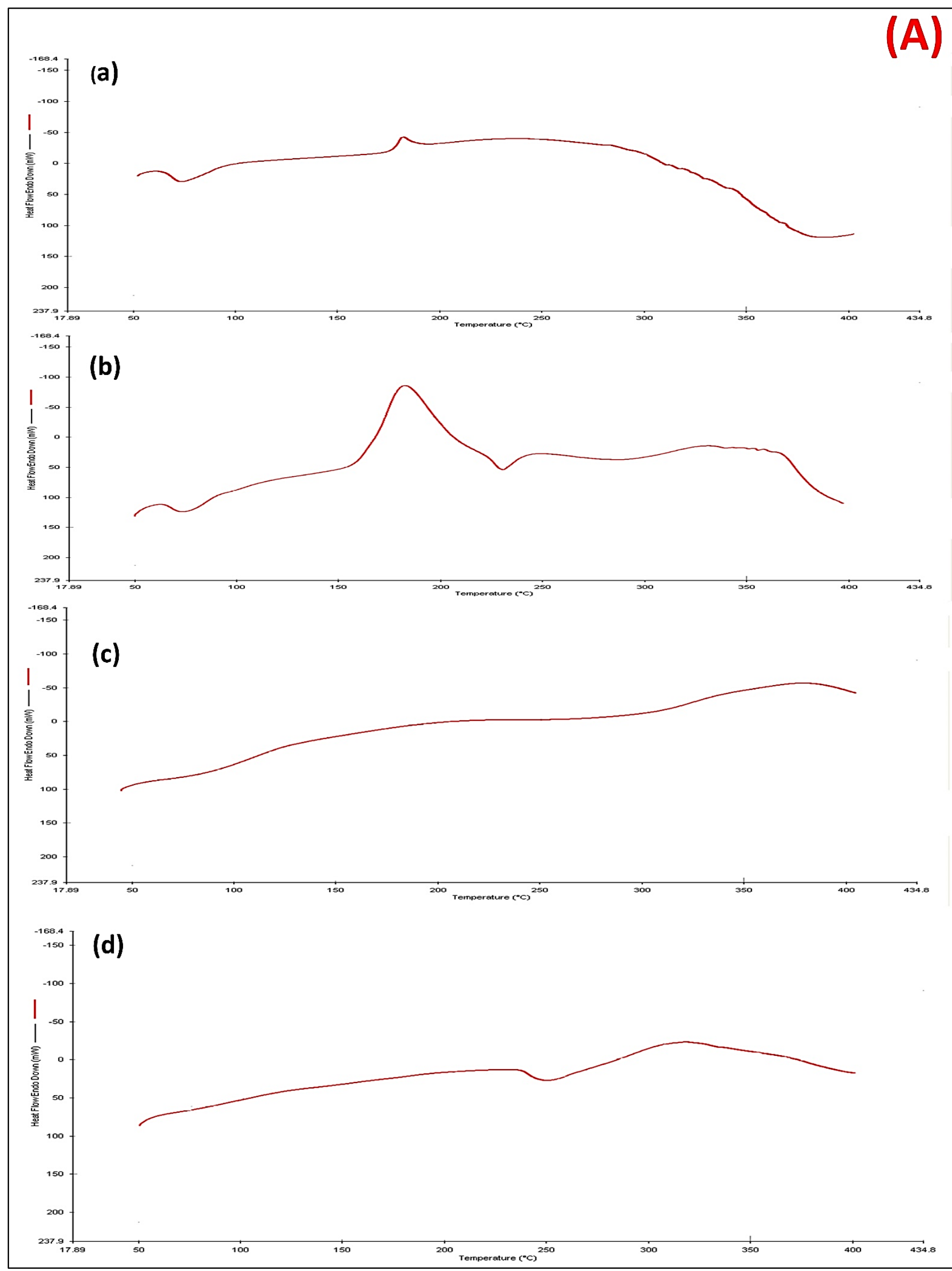

Figure 2A. DSC thermograms of PEO (a), ALF-PEO physical mixture (b), CP 934 (c), ALF-CP physical mixture (d). 

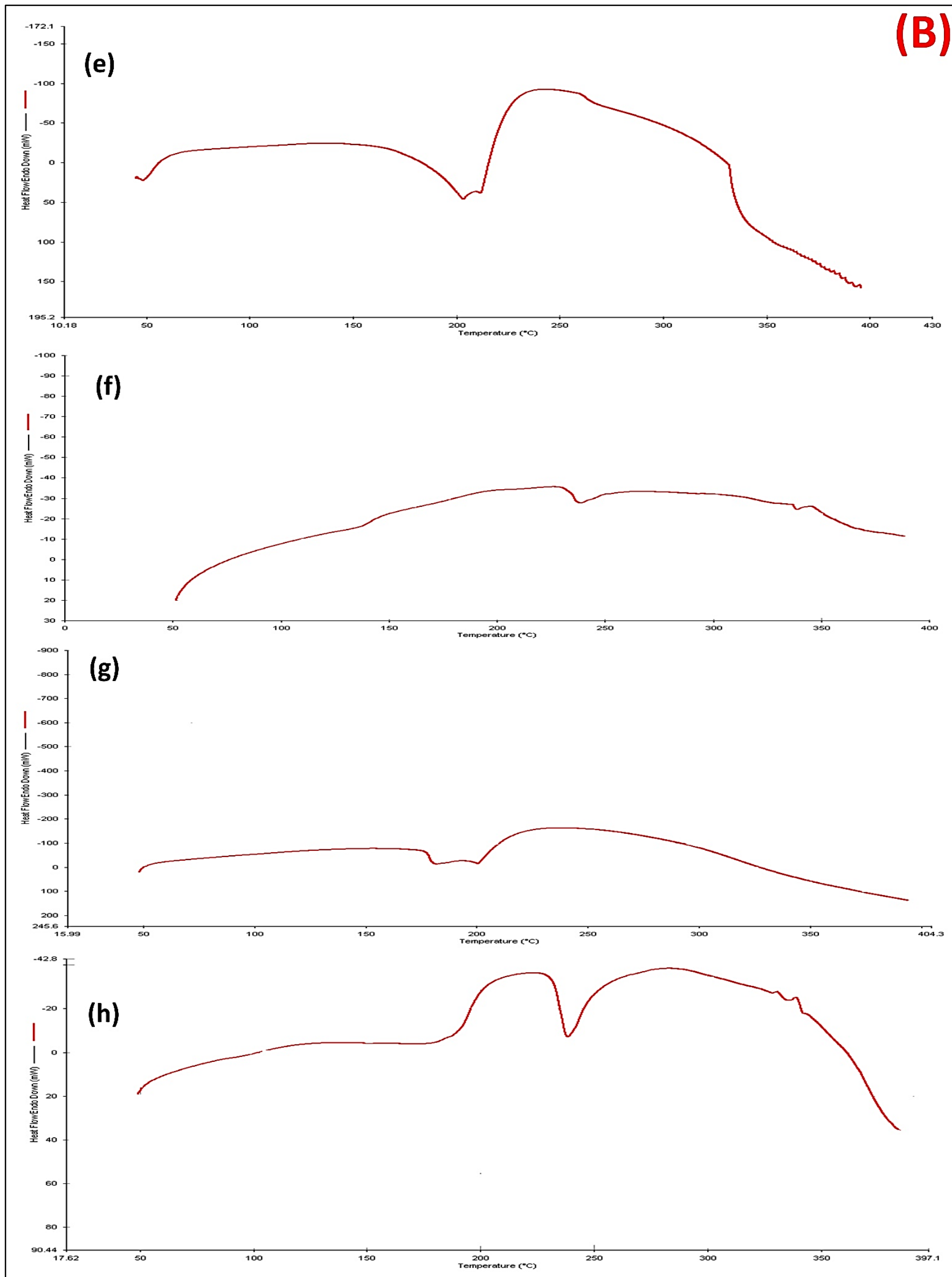

Figure 2B. DSC thermograms of menthol (e), ALF-menthol physical mixture (f), camphor (g) and ALF-camphor physical mixture (h). 
in the DSC thermograms of ALF-excipient physical mixtures could ascertain their physical compatibility and the permanence of the drug in the crystalline state.

\subsection{In-vitro assessment of ALF-loaded tablets}

\subsubsection{Visual inspection}

The developed PEO- and CP-based tablets had good appearance, homogeneous texture and thickness and kept their physical integrity showing no cracks either before or after sublimation.

\subsubsection{Hardness}

Hardness results of the developed PEO-based tablets (F1-F8) and CP-based tablets (F9-F16) are represented in Table 1. The 3D response surface plots revealing the effect of the independent variables; polymer type (A), sublimable agent type (B) and sublimable agent concentration (C) on tablet hardness were illustrated in Figure 3(a). The derived equation for the determination of hardness would be;

Hardness $=+5.54+0.074 * \mathrm{~A}+0.056 * \mathrm{~B}+0.31$

$* \mathrm{C}[1]+0.10 * \mathrm{C}[2]-0.032 * \mathrm{C}[3]$

The polymer type (A) displayed a positive significant impact on tablet hardness $(p=0.0321)$. CPbased tablets showed higher crushing strength values than PEO-based ones.

These findings were in line with those reported by Kasperek et al. ${ }^{31}$, who found that Avicel PH 102-based papaverine tablets had better mechanical resistance and improved hardness, compared to Avicel PH 101-based ones.

In contrast, the sublimable agent concentration (C) possessed a negative significant impact on tablet hardness $(p<0.0001)$. It was observed that increasing the concentration of the sublimable agent caused a decrease in tablet hardness. This could be attributed to the higher tablet porosity, resulting from the evaporation of higher amounts of the sublimable agents. Additionally, the increase in the sublimable agent concentration was accompanied with a decrease in the polymer concentration and this could also affect tablet hardness. Similar findings were reported by Kim et al. ${ }^{5}$ for itraconazole gastroretentive tablets and by $\mathrm{Oh}$ et al. ${ }^{4}$ for metformin gastroretentive tablets. It was revealed that the increase in the amount of camphor in the matrix tablets was accompanied by a decrease in their crushing strength after sublimation. On the other hand, sublimable agent type (B) had no significant impacts on tablet hardness $(p=0.0803)$. This pattern was similarly reported by Kamboj et al. ${ }^{32}$, who revealed the absence of significant differences in the hardness values of sublimable metformin tablets that were prepared using either ammonium bicarbonate or camphor as sublimable materials.

\subsubsection{Friability}

Friability results of the developed tablets were found to be matched with hardness results, Table 1 . The $3 \mathrm{D}$ response surface plots indicating the effect of the independent variables; polymer type (A), sublimable agent type (B) and sublimable agent concentration (C) on tablet friability were illustrated in Figure 3(b). The derived equation for the determination of friability would be,

$\operatorname{Ln}($ friability +0.01$)=-2.50+1.33 * \mathrm{~A}-0.020 *$ $\mathrm{B}+0.27 * \mathrm{C}[1]-0.44 * \mathrm{C}[2]+0.66 * \mathrm{C}[3]$

The polymer type (A) possessed a positive significant impact on tablet friability $(p=0.002)$. CPbased tablets showed higher friability percentage values than PEO-based ones. However, the sublimable agent type (B) and the sublimable agent concentration (C) displayed non-significant influences on tablet friability ( $p=0.9512$ and $p=0.5419$, respectively). According to Kamboj et $\mathrm{al}^{32}$, the friability percentages of ammonium bicarbonate-based and camphor-based sublimable metformin tablets were non-significantly different, regardless of the sublimable agent concentration.

\subsubsection{Density}

All the developed tablets showed lower bulk density values than that of the gastric fluid. The results varied from $0.71 \mathrm{~g} / \mathrm{cm}^{3}(\mathrm{~F} 8)$ to $0.91 \mathrm{~g} / \mathrm{cm}^{3}(\mathrm{~F} 1)$, as shown in Table 1. It would be expected that the developed tablets could have good buoyancy characteristics due to such low bulk density values. The 3D response surface plots revealing the effect of the independent variables; polymer type (A), sublimable agent type (B) and sublimable agent concentration (C) on tablet density were illustrated in Figure 3(c). The derived equation for the determination of tablet density would be,

Density $=+0.83+0.018 * \mathrm{~A}-0.021 * \mathrm{~B}+0.079$

$* \mathrm{C}[1]+0.026 * \mathrm{C}[2]-0.021 * \mathrm{C}[3]$

The polymer type (A) possessed a positive significant influence on tablet density ( $p=0.0006)$; PEObased tablets exhibited significant lower bulk density values than $\mathrm{CP}$-based ones. According to $\mathrm{Oh}$ et al. ${ }^{4}$, this could be due to the slight increase in the thickness of PEO-based tablets after sublimation comparing with CP-based ones; causing a decrease in their bulk densities.

In contrast, the sublimable agent type (B) and the sublimable agent concentration $(\mathrm{C})$ had negative significant impacts on tablet density $(p=0.0001$ and $p<0.0001$, respectively). The tablets which were prepared with 1-menthol exhibited significant lower bulk density values than those prepared using camphor. It could be deduced that larger pores could be created after menthol sublimation, compared to those created after camphor sublimation resulting in a lower bulk density $^{33}$. On the other hand, increasing the sublimable 


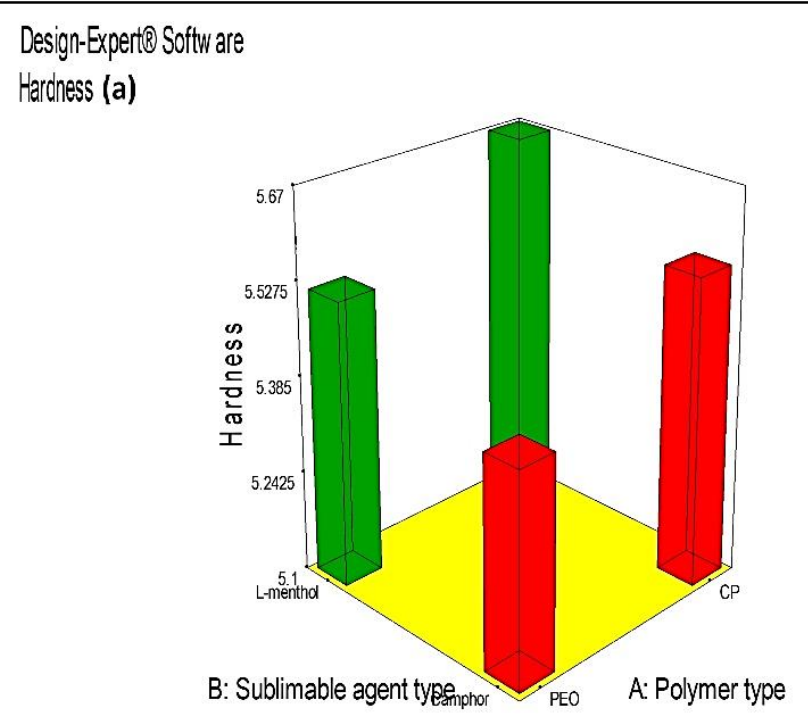

Friability (b)

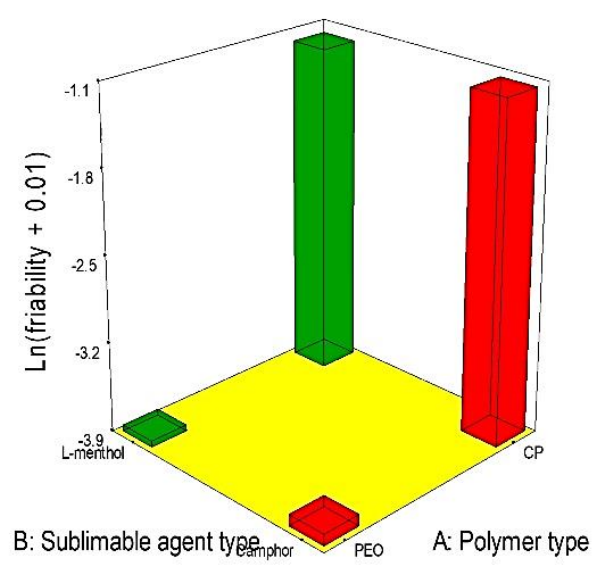

\section{Density (c)}

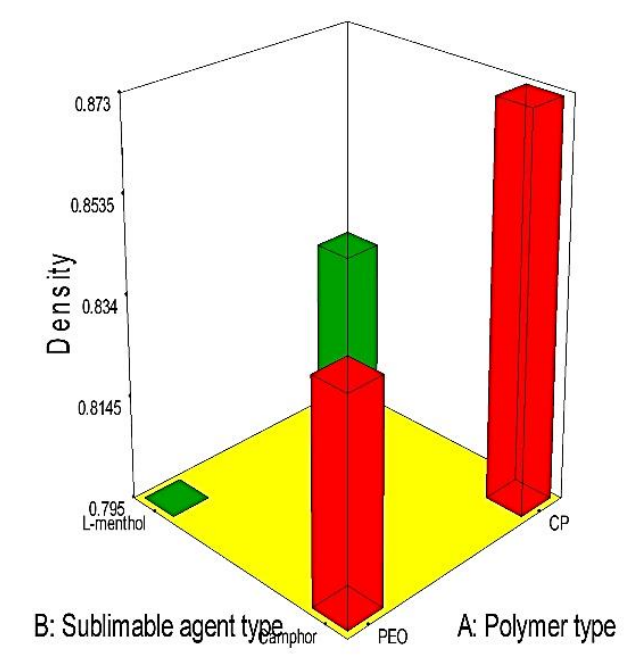

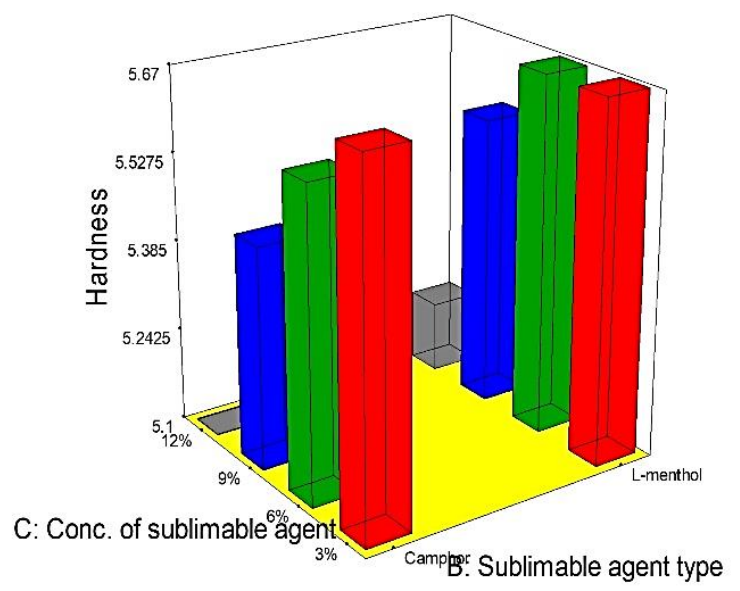
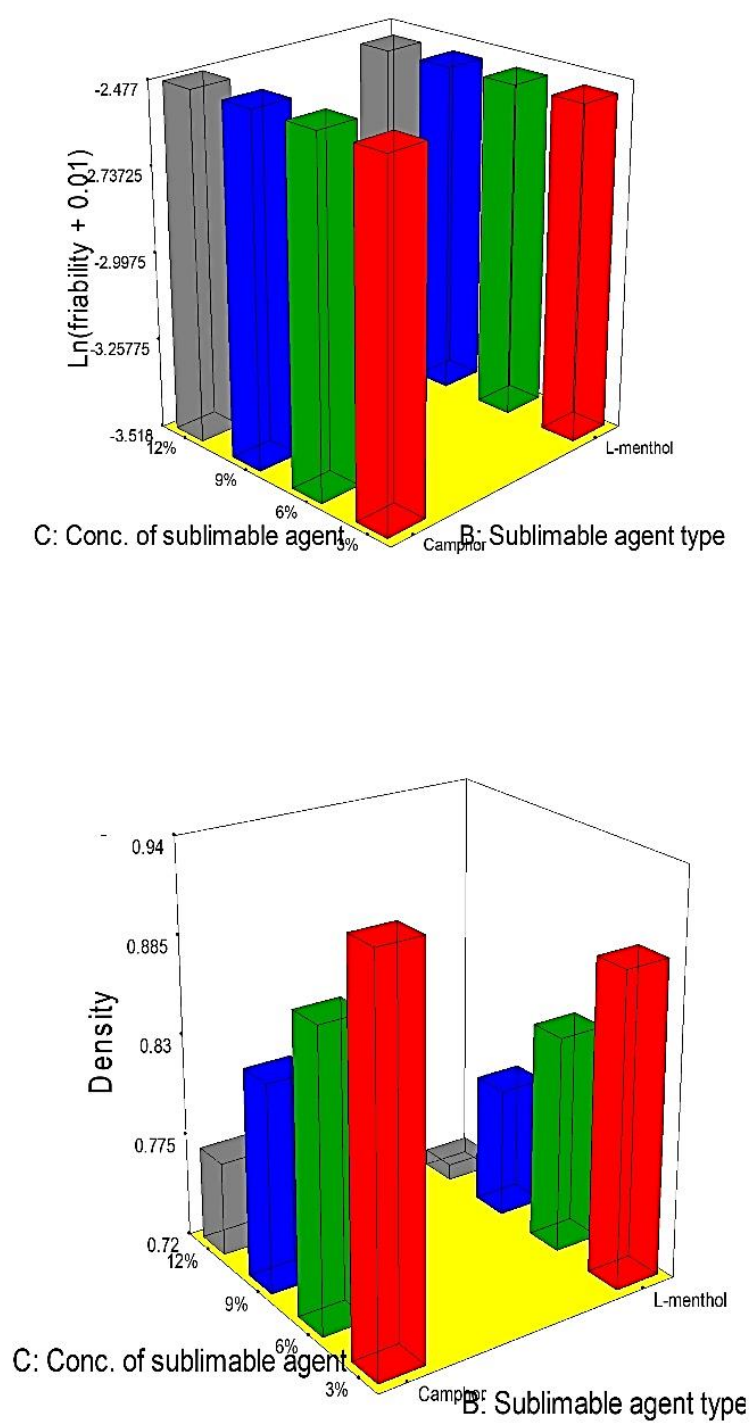

Figure 3. The 3D response surface plots for the effect of the independent variables; polymer type (A), sublimable agent type (B) and sublimable agent concentration (C) on the tablet hardness (a), friability (b) and density (c). 


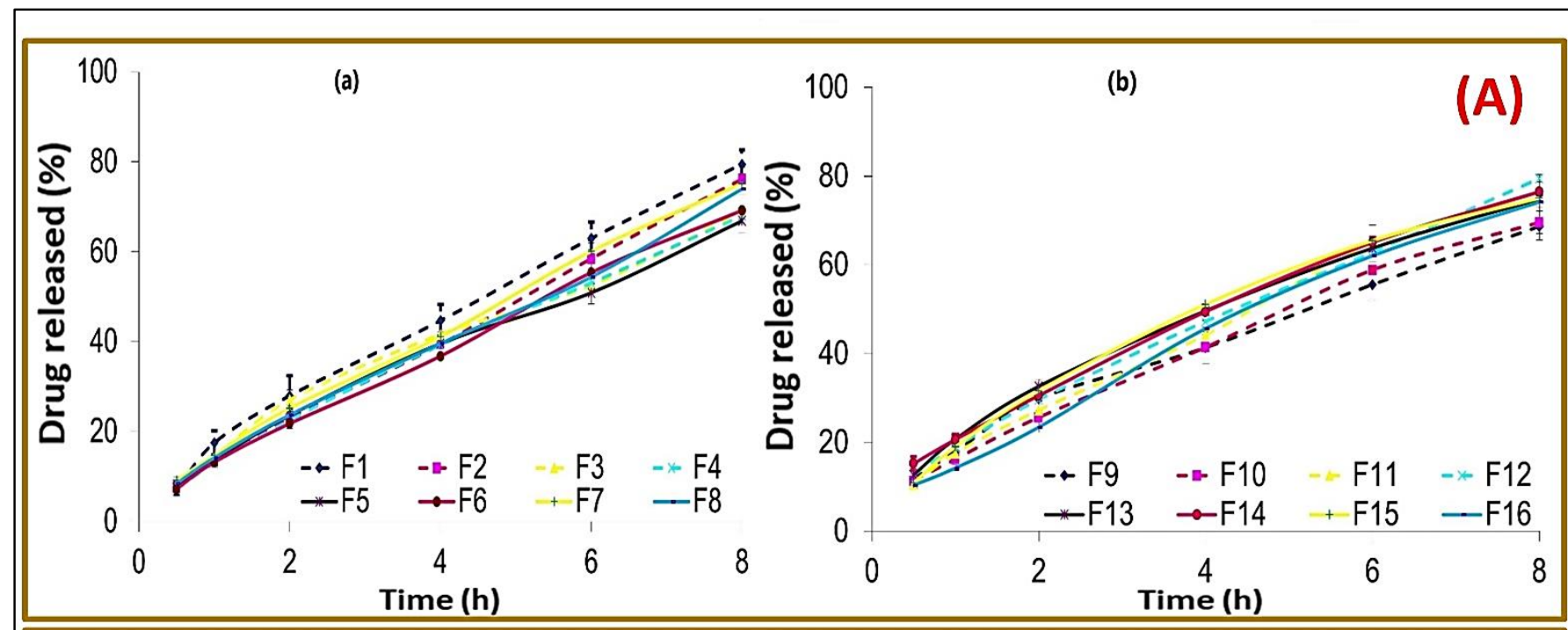

Design-Expert国 Software

Q.5h (a)
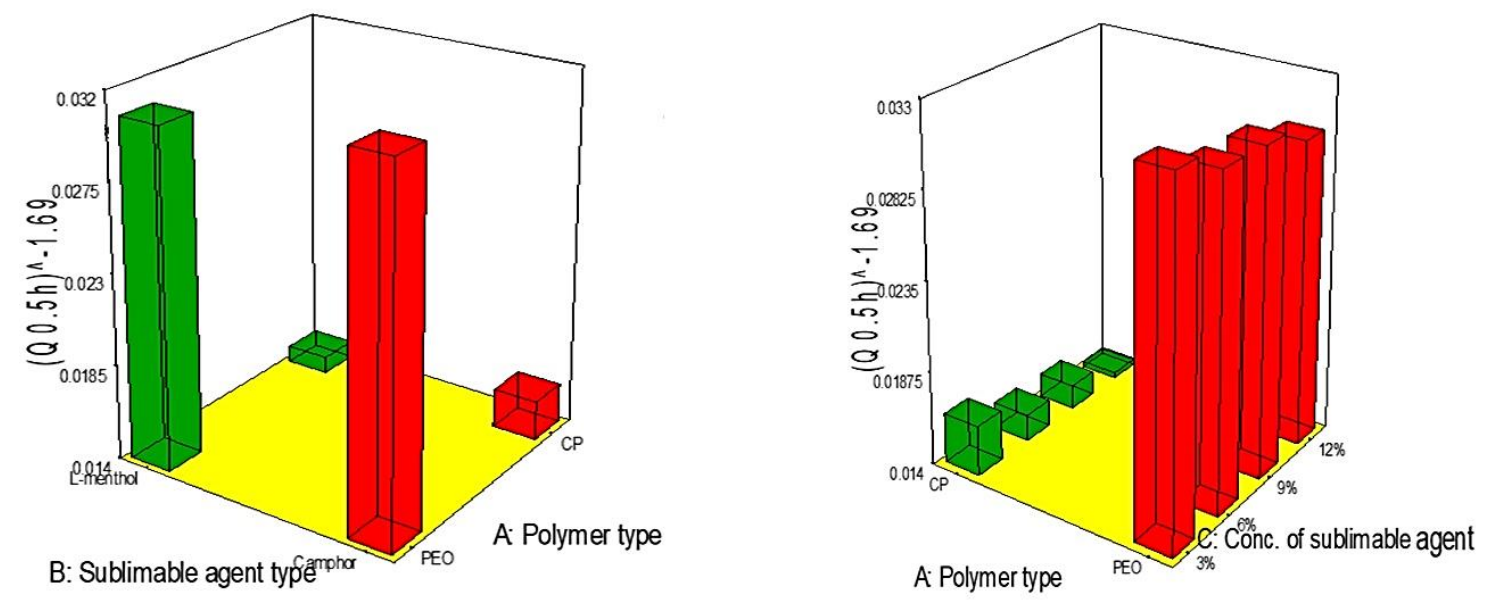

$Q_{8 h}$ (b)
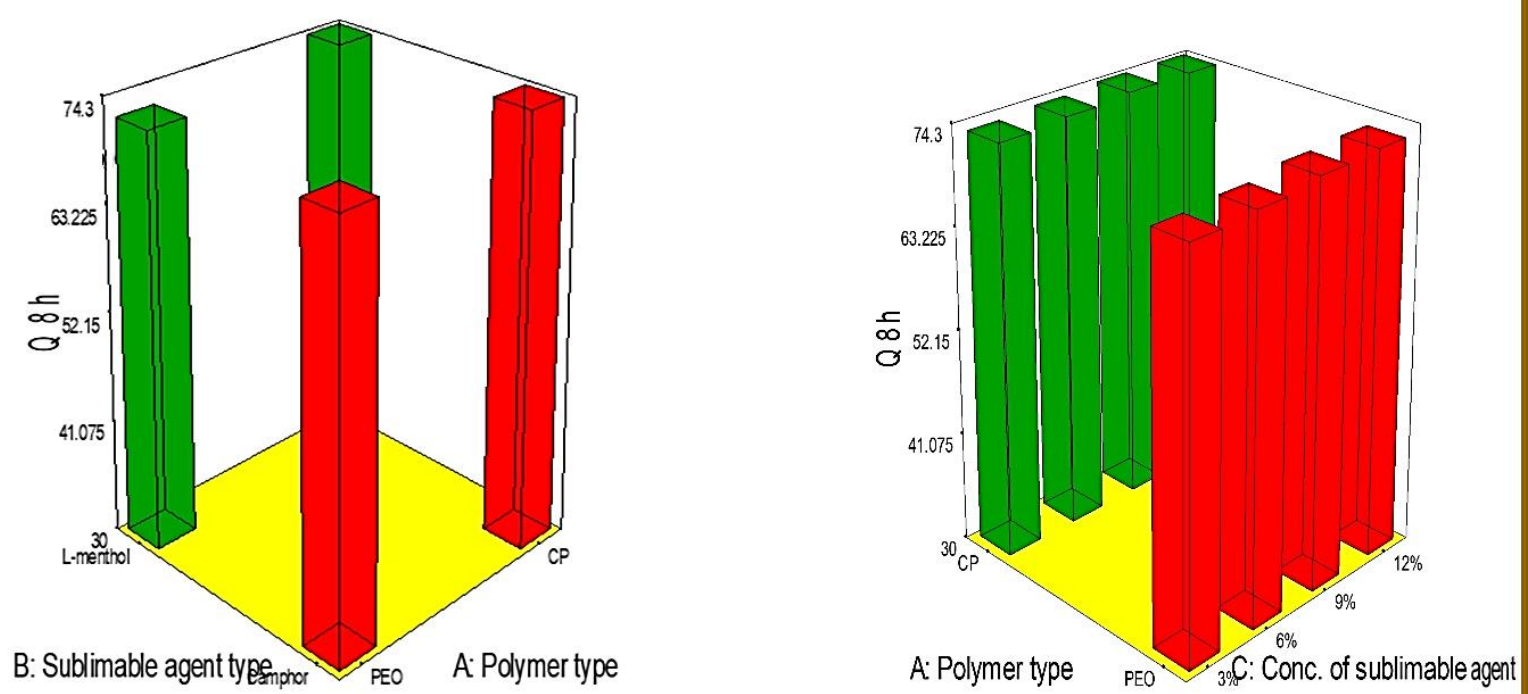

Figure 4. A. In vitro drug release profiles of PEO-based floating tablets (a) and CP-based floating tablets (b) in $0.1 \mathrm{~N} \mathrm{HCl}$ at $37 \pm 0.5^{\circ} \mathrm{C}$ $($ mean $\pm \mathrm{SD}, \mathrm{n}=3)$. B. The $3 \mathrm{D}$ response surface plots for the effect of polymer type (A), sublimable agent type (B) and sublimable agent concentration (C) on $\mathrm{Q}_{0.5 \mathrm{~h}}(\mathrm{a})$ and $\mathrm{Q}_{8 \mathrm{~h}}(\mathrm{~b})$. 


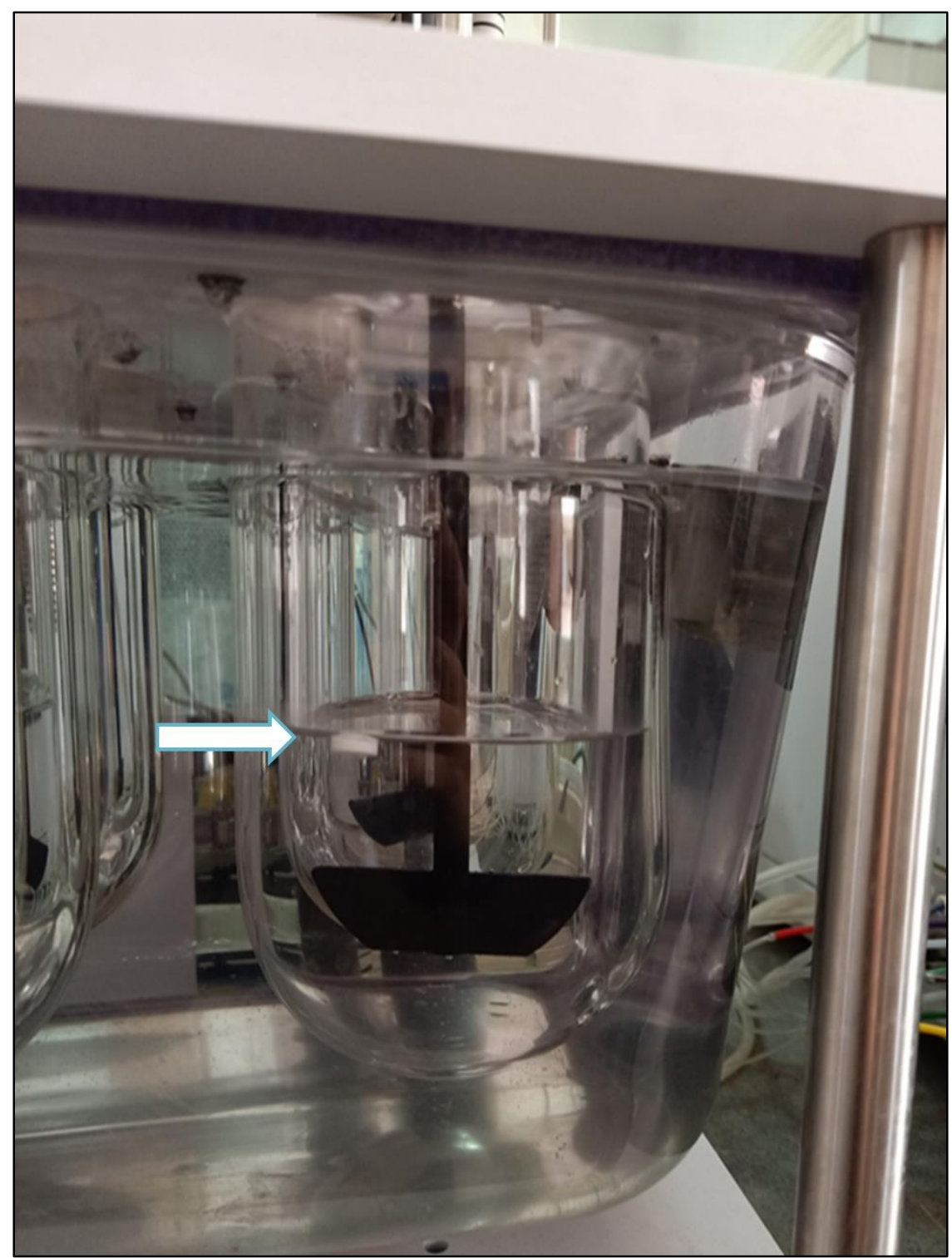

Figure 5. A photograph taken during in vitro drug release studies of $\mathrm{F} 1$ in $0.1 \mathrm{~N} \mathrm{HCl}$.

agent concentration was accompanied with a decrease in tablet density. This could be returned to the higher porosity resulted from evaporation of a higher amount of the sublimable agent. Additionally, the increase in the sublimable agent concentration would be accompanied with a decrease in polymer concentration resulting in a larger thickness of the tablet that would aid in decreasing its density ${ }^{7}$.

\subsubsection{In vitro drug release studies}

The In vitro drug release studies were conducted in $0.1 \mathrm{~N} \mathrm{HCl}$ at $37 \pm 0.5^{\circ} \mathrm{C}$, as previously reported for the development of ALF-loaded gastroretentive dosage forms ${ }^{11-12}$. Figure 4(A) showed the in vitro release profiles of ALF from PEO-based tablets (F1-F8; a) and CP-based tablets (F9-F16; b) in $0.1 \mathrm{~N} \mathrm{HCl}$.

Table 1 showed that all the developed tablets had promising sustained drug release profiles. The drug released \% after $0.5 \mathrm{~h}\left(\mathrm{Q}_{0.5 \mathrm{~h}}\right)$ ranged from $7.01 \%(\mathrm{~F} 1)$ to $15.30 \%$ (F14) while those released after $8 \mathrm{~h}\left(\mathrm{Q}_{8 \mathrm{~h}}\right)$ varied from $66.90 \%$ (F5) to $79.51 \%$ (F1). Figure 4(B) shows 3D response surface plots which were used to reveal the impact of the independent variables; polymer type (A), sublimable agent type (B) and sublimable agent concentration $(C)$ on $\mathrm{Q}_{0.5 \mathrm{~h}}(\mathrm{a})$ and $\mathrm{Q}_{8 \mathrm{~h}}(\mathrm{~b})$. The obtained equations for the determination of $\mathrm{Q}_{0.5 \mathrm{~h}}$ and $\mathrm{Q}_{8 \mathrm{~h}}$ would be;

$$
\begin{aligned}
& \mathrm{Q}_{0.5 \mathrm{~h}}=+10.40+0.83 * \mathrm{~A}[1]-2.47 * \mathrm{~A}[2]+0.28 * \mathrm{~B}(6) \\
& \mathrm{Q}_{8 \mathrm{~h}}=+73.25+0.98 * \mathrm{~A}+0.023 * \mathrm{~B}-0.74 * \mathrm{C}[1]-
\end{aligned}
$$

$0.35 * \mathrm{C}[2]+0.40 * \mathrm{C}[3]$

The polymer type (A) displayed a positive significant impact on $\mathrm{Q}_{0.5 \mathrm{~h}}(p<0.0001)$. However, it had no significant impact on $\mathrm{Q}_{8 \mathrm{~h}}(p=0.4309)$. CP-based tablets exhibited initial fast drug release that could be attributed to the absorption of the maximum amount of water by $\mathrm{CP}$ at the first two hours, allowing for the release of high drug percentages ${ }^{34}$. Similar findings 
were reported by Varma et al. ${ }^{35}$, for CP-based diltiazem hydrochloride hydrophilic matrices. It is worth to note that the sublimable agent type (B) and the sublimable agent concentration (C) had non-significant impacts on $\mathrm{Q}_{0.5 \mathrm{~h}}\left(p=0.5615\right.$ and $p=0.8455$, respectively) or $\mathrm{Q}_{8 \mathrm{~h}}$ ( $p=0.9849$, and $p=0.9712$, respectively); suggesting that drug release from the tablets was controlled only by polymer nature, rather than the density or porosity of the tablets. Comparable results were reported by Oh et al. ${ }^{4}$ for metformin tablets and Saab et al. ${ }^{36}$ for sulbutamol sulfate tablets.

Among the investigated kinetic models, Korsmayer-peppas was the best-fitting model for drug release data since it revealed the highest correlation coefficient $\left(\mathrm{r}^{2}\right)$ values. The release exponent $(\mathrm{n})$ values ranged from 0.45 to 0.89 , suggesting the predominance of the non-Fickian (anomalous) diffusion. It could be inferred that both diffusion and erosion drug release mechanisms are involved $^{20}$.

\subsubsection{Assessment of the floating behavior}

Excellent floating characteristics were observed for all tablets, Figure 5. They displayed zero floating lag time and prolonged floating durations for at least $8 \mathrm{~h}$. This could be attributed to the large no. of pores which were created after menthol/camphor sublimation. This allowed the tablet matrix to have a low bulk density and a porous structure ${ }^{36}$. A similar pattern was noted by Kim et al. ${ }^{5}$. It was revealed that the sublimation of camphor decreased the density of itraconazole gastroretentive tablets by generating pores in the tablet matrices and hence, they showed zero floating lag times. In a parallel line, Oh et al. ${ }^{4}$ showed that the sublimable metformin tablets had zero floating lag times and were able to float for more than $24 \mathrm{~h}$.

\subsection{Selection of the best achieved floating tablets}

The values of hardness, friability, density and $\mathrm{Q}_{0.5 \mathrm{~h}}$ were subjected to polynomial analysis. The main effects model was utilized for the analysis of all the dependent variables except friability where it utilized the reduced main effects model. Table 2 showed ANOVA results that clarified the significance of the utilized models. This could be revealed through the displayed large $\mathrm{F}$ values. There is a probability of $0.35 \%$ only that noise could cause such large values ${ }^{37-38}$.

In addition, it was observed that the $\mathrm{R}^{2}$ values were close to unity $(0.8915,0.5812,0.9717$ and 0.8822$)$, indicating a good correlation between the anticipated and the investigated values. The acceptable differences $(<0.20)$ between the predicted $\mathrm{R}^{2}$ and the adjusted $\mathrm{R}^{2}$ could also confirm the above suggestion ${ }^{39-40}$. Moreover, the low values of the coefficient of variation (C.V.) percentages $(2.14 \%, 4.56 \%, 1.71 \%$ and $15.88 \%)$ and the standard deviations $\left(0.12,1.21,0.01\right.$ and $\left.3.71 \times 10^{-3}\right)$ along with the large adequate precision values $(>4)$ reflected the precision and adequacy with which the experiments were conducted as well as the potential of the investigated models to express the design space ${ }^{41}$.

Numerical optimization was applied to the set constrains so that the friability and $\mathrm{Q}_{0.5 \mathrm{~h}}$ were intended to achieve minimum values; the hardness was targeted to attain maximum values; while the density was designed to be lower than $1 \mathrm{~g} / \mathrm{cm}^{3}$. Based on the estimated desirability values, the optimum system could be selected. The highest desirability value $(0.876)$ was achieved with F1 (PEO-based tablets containing camphor; $3 \%, \mathrm{w} / \mathrm{w})$. The predicted values for friability $(0.03 \%)$ and $\mathrm{Q}_{0.5 \mathrm{~h}}(7.51 \%)$ and hardness $\left(5.72 \mathrm{Kg} / \mathrm{cm}^{2}\right)$ values were close to the experimental results, Table 2 . Consequently, F1 was promoted for further investigations.

\subsection{Characterization of the best achieved floating tablets}

\subsubsection{Structural observation of the best achieved tablets}

Representative scanning electron micrographs of ALF-loaded PEO-based floating tablets (F1) before(a) and after-camphor sublimation (b) were presented in Figure 6.

Before sublimation, the tablet showed a nonporous and dense structure. Following camphor sublimation, it showed a highly porous structure with wide pore diameters of several micrometers. Such porous structure was responsible for the excellent floating characteristics of the tablets.

\subsubsection{Gastroretentive tracking of the best achieved tablets via MRI}

The best achieved floating tablets (F1) were loaded with magnetite. Magnetite is a negative contrast agent that could influence the magnetization of the surrounded tissues, giving rise to an intense T2 signal permitting the clear visualization of tablets in the stomach $^{15,21}$.

Figure 7 illustrates the magnetic resonance images of a subject in both the axial [A] and coronal [B] views. Prior dosing $(0 \mathrm{~h})$, the stomach was free from any magnetite-loaded medication. Up to 5 hours postdosing, the magnetite-loaded tablets were detected as floating matrices over the gastric fluids in relatively unstable gastric positions. It is worth to note that a gradual increase in the size of the tablets was observed in all subjects. This was followed by tablet fragmentation and erosion. Hassling results were reported by Tadros and Fahmy ${ }^{21}$ for lornoxicam-loaded sponges and Abd El-Aziz et al. ${ }^{12}$ for ALF-loaded sponges. 


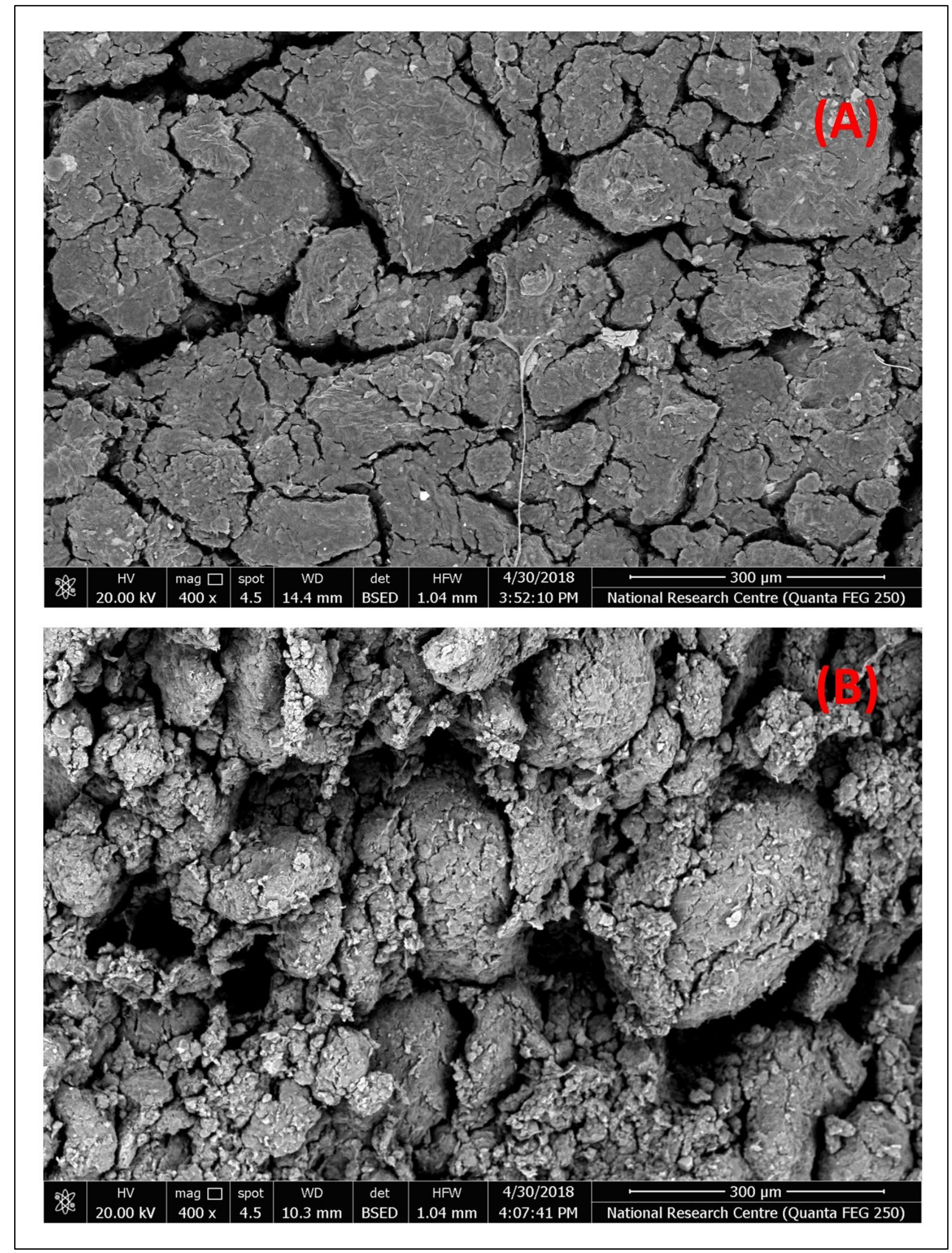

Figure 6. Scanning electron micrographs of the optimized formula (F1) before sublimation (a) and after sublimation (b). 

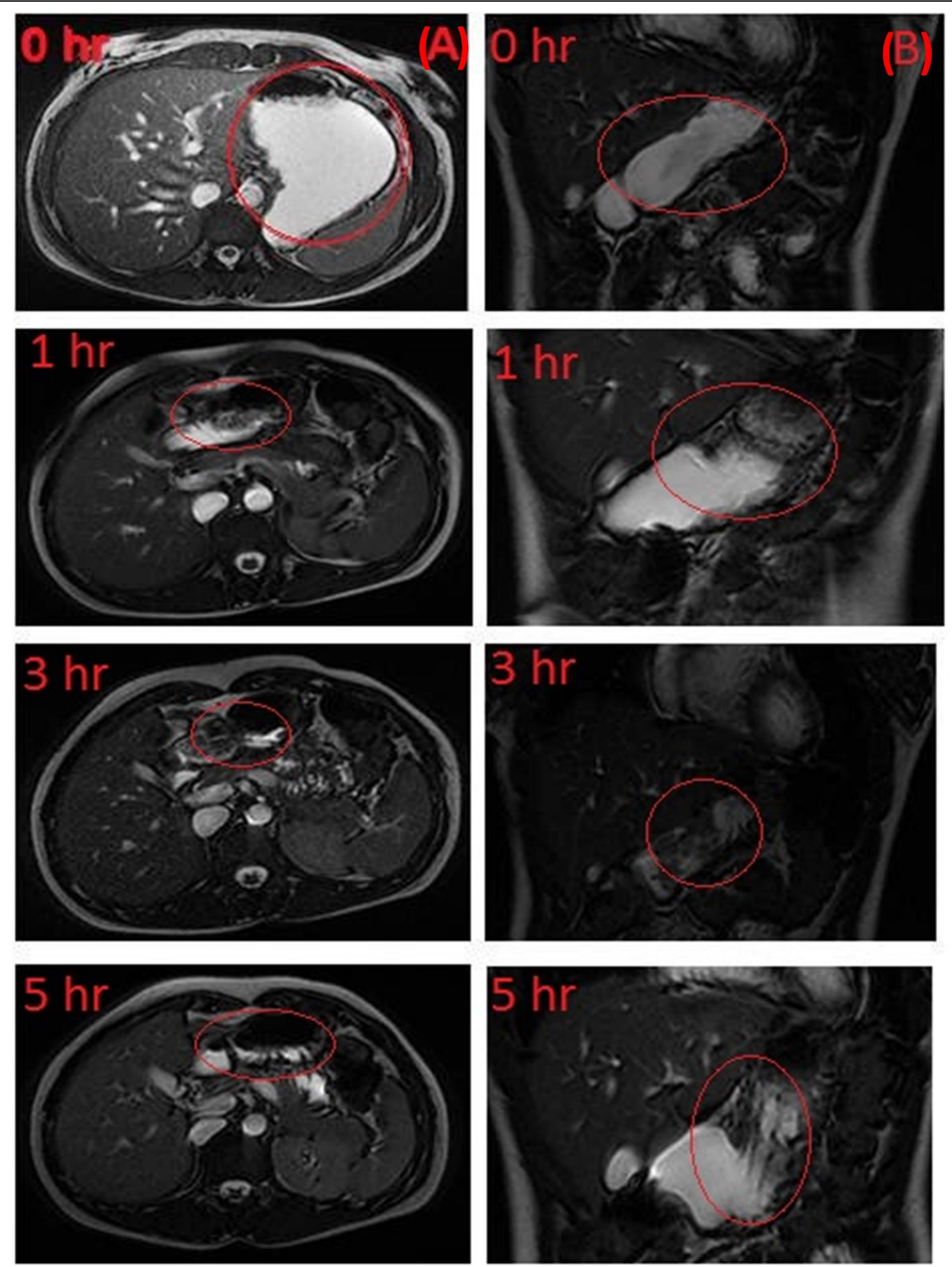

Figure 7. Magnetic resonance images of a subject in axial $[\mathrm{A}]$ and coronal $[\mathrm{B}]$ views, at various time intervals up to 5 hours. 


\section{CONCLUSIONS}

Auspicious low-density floating ALF-loaded PEO- and CP-based gastroretentive tablets were successfully developed following the sublimation of camphor and l-menthol. The developed tablets exhibited acceptable physicochemical properties and possessed excellent floating characteristics and were able to sustain the rate of ALF release for at least 8 hours. The highest desirability value $(0.876)$ was achieved with F1 (PEO-based tablets containing camphor; 3\%, w/w) with respect to minimum friability $(0.03 \%)$, minimum $\mathrm{Q}_{0.5 \mathrm{~h}}$ $(7.51 \%)$ and maximum hardness $\left(5.72 \mathrm{Kg} / \mathrm{cm}^{2}\right)$ values. Furthermore, it had a porous structure, low bulk density $\left(0.91 \mathrm{~g} / \mathrm{cm}^{3}\right)$ and possessed excellent floating characterristics with respect to zero floating lag time and prolonged floating duration (> $8 \mathrm{~h}$ ). MRI of the magnetite-loaded F1 floating tablets revealed the in vivo gastroretentive potential of this system for at least 5 hours.

\section{ACKNOWLEDGMENT}

The authors received no scholarship or grant for conducting this work.

\section{Conflict of interest}

The authors report no conflict of interest.

\section{Funding}

None to declare.

\section{Ethics approval}

The study protocol was approved (PI 975) by the research ethics committee for clinical studies at Faculty of Pharmacy, Cairo University, Egypt.

\section{Article info:}

Received May 27, 2020

Received in revised form October 24, 2020

Accepted December 9, 2020

\section{REFERENCES}

1. Stojanovska M, Petruševski VM, Šoptrajanov B. The concept of sublimation-Iodine as an example. Educ Quimica. 2012;23(1): 171-5.

2. Latyshev AV, Fedina LI, Kosolobov SS, Sitnikov SV, Rogilo DI, Rodyakina EE, et al. Atomic processes on the silicon surface. In: Latyshev AV, Dvurechenskii AV, Aseev AL, editors. Advances in semiconductor nanostructures: Growth, characterization, properties and applications. $1^{\text {st }}$ ed. Amsterdam: Elsevier Science Inc.; 2017. p. 189-221.

3. Faghri A, Zhang Y. Sublimation and vapor deposition. In: Faghri A, Zhang Y, editors. Transport phenomena in multiphase systems. $1^{\text {st }}$ ed. UT: Academic Press; 2006. p.531-80.

4. Oh TO, Kim JY, Ha JM, Chi SC, Rhee YS, Park CW, et al. Preparation of highly porous gastroretentive metformin tablets using a sublimation method. Eur J Pharm Biopharm. 2013;83(3): 460-7.

5. Kim JY, Rhee YS, Park CW, Ha JM, Park ES. Preparation and evaluation of dual-mode floating gastroretentive tablets containing itraconazole. Drug Deliv. 2014;21(7):519-29.

6. Yehia SA, El-Ridi MS, Tadros MI, El-Sherif NG. Phenylalanine-free taste-masked orodispersible tablets of fexofenadine hydrochloride: Development, in vitro evaluation and in vivo estimation of the drug pharmacokinetics in healthy human volunteers. Pharm Dev Technol. 2015;20(5):528-39.

7. Kesarla RS, Vora PA, Sridhar BK, Patel G, Omri A. Formulation and evaluation of floating tablet of H2-receptor antagonist. Drug Dev Ind Pharm. 2015;41(9):1499-511.

8. Liu Q, Fassihi R. Zero-order delivery of a highly soluble, low dose drug alfuzosin hydrochloride via gastro-retentive system. Int J Pharm. 2008;348:27-34.

9. Fahmy RH. Statistical approach for assessing the influence of calcium silicate and hpmc on the formulation of novel alfuzosin hydrochloride mucoadhesive-floating beads as gastroretentive drug delivery systems. AAPS PharmSciTech. 2012;13(3):9901004.

10. Pagariya TP, Patil SB. Development and optimization of multiparticulate drug delivery system of alfuzosin hydrochloride. Colloids Surf B. 2013;102:171-7.

11. Gong L, Sun Y, Yu M, Gao Y, Zou M, Cheng G. Development and evaluation of compression coating gastro-floating tablet of alfuzosin hydrochloride for zero-order controlled release. AAPS PharmSciTech. 2018;19(7):3277-86.

12. Abd El-Aziz MF, Ismail S, Tadros MI, El-Nabarawi MA. Alfuzosin hydrochloride-loaded low-density gastroretentive sponges: development, in vitro characterization and gastroretentive monitoring in healthy volunteers via MRI. Pharm Dev Technol. 2020;25(5):566-78.

13. Tadros MI. Controlled-release effervescent floating matrix tablets of ciprofloxacin hydrochloride: Development, optimization and in vitro-in vivo evaluation in healthy human volunteers. Eur J Pharm Biopharm. 2010;74(2):332-9.

14. Razavi M, Karimian H, Yeong CH, Chung LY, Nyamathulla S, Noordin MI. Gamma scintigraphic evaluation of floating gastroretentive tablets of metformin $\mathrm{HCl}$ using a combination of three natural polymers in rabbits. Drug Des Devel Ther. 2015;9: 4373-86.

15. Knörgen M, Spielmann RP, Abdalla A, Metz H, Mäder K. Noninvasive MRI detection of individual pellets in the human stomach. Eur J Pharm Biopharm. 2010;74(1):120-5.

16. Tayel SA, El-Nabarawi MA, Tadros MI, Abd-Elsalam WH. Duodenum-triggered delivery of pravastatin sodium via enteric surface-coated nanovesicular spanlastic dispersions: Development, characterization and pharmacokinetic assessments. Int J Pharm. 2015;483(1-2):77-88.

17. Lee AR, Kwon SY, Choi DH, Park ES. Quality by Design (QbD) approach to optimize the formulation of a bilayer combination tablet $\left(\right.$ Telmiduo ${ }^{\circledR}$ ) manufactured via high shear wet granulation. Int J Pharm. 2017;534(1-2):144-58

18. Paul S, Sun CC. Systematic evaluation of common lubricants for optimal use in tablet formulation. Eur J Pharm Sci. 2018; 117:118-27.

19. Shirguppe AP, Belekar AM, Salian PS. Formulation and evaluation of floating sustained release in situ gel as carrier for stomach specific drug delivery of alfuzosin. Int J Adv Res Ideas Innov Technol. 2018;4(1):775-83.

20. Abd-Elbary A, Tadros MI, Alaa-Eldin AA. Sucrose stearateenriched lipid matrix tablets of etodolac: Modulation of drug release, diffusional modeling and structure elucidation studies. AAPS PharmSciTech. 2013;14(2):656-68.

21. Steingoetter A, Weishaupt D, Kunz P, Mäder K, Lengsfeld H, Thumshirn M, et al. Magnetic resonance imaging for the in vivo evaluation of gastric-retentive tablets. Pharm Res. 2003;20(12): 2001-7.

22. Tadros MI, Fahmy RH. Controlled-release triple antiinflammatory therapy based on novel gastroretentive sponges: Characterization and magnetic resonance imaging in healthy 
volunteers. Int J Pharm. 2014;472(1-2):27-39.

23. Pickelmann J, Plank J. A mechanistic study explaining the synergistic viscosity increase obtained from polyethylene oxide (PEO) and $\beta$-naphthalene sulfonate (BNS) in shotcrete. Cem Concr Res. 2012;42(11):1409-16.

24. Srikanth MV, Rao NS, Sunil SA, Ram BJ, Ramana V, Kolapalli $\mathrm{M}$. Statistical design and evaluation of a propranolol $\mathrm{HCl}$ gastric floating tablet. Acta Pharm Sin B. 2012;2(1):60-9.

25. Ali A, Khalid I, Minhas MU, Barkat K, Khan IU, Syed HK. Preparation and in vitro evaluation of chondroitin sulfate and carbopol based mucoadhesive controlled release polymeric composites of loxoprofen using factorial design. Eur Polym J. 2019;121:109312.

26. Schulz H, Özkan G, Baranska M, Krüger H, Özcan M. Characterisation of essential oil plants from Turkey by IR and Raman spectroscopy. Vib Spectrosc. 2005;39:249-56.

27. Soottitantawat A, Takayama K, Okamura K, Muranaka D, Yoshii H, Furuta T. Microencapsu- lation of 1-menthol by spray drying and its release characteristics. Innov Food Sci Emerg Technol. 2005;6:163-70.

28. Santos MG, Carpinteiro DA, Thomazini M, Rocha-Selmi GA, da Cruz AG, Rodrigues CEC et al. Coencapsulation of xylitol and menthol by double emulsion followed by complex coacervation and microcapsule application in chewing gum. Food Res Int. 2014;66:454-62.

29. Reddy MR, Subrahmanyam AR, Reddy MM, Kumar JS, Kamalaker V, Reddy J. X-RD, SEM, FT-IR, DSC Studies of Polymer Blend Films of PMMA and PEO. Mater Today Proc. 2016;3(10):3713-18.

30. Lei HP, Zhang H, Ge FH, Ye ZW, Li CH. Preparation of a menthol/beta-cyclodextrin inclusion complex using supercritical CO2. Indian J Pharm Sci. 2018;80(4):766-71.

31. Kasperek R, Polski A, Sobótka-Polska K, Poleszak E. Influence of polymer type on the physical properties and the release study of papaverine hydrochloride from tablets. Polim Med. 2014;
44(1):5-12.

32. Kamboj M, Goyal S, Rakha P, Arora G, Dureja H, Nagpal M. Formulation and evaluation of metformin oro-dispersible tablets. Acta Pol Pharm. 2011;68(5):717-23.

33. Hwang KM, Cho CH, Tung NT, Kim JY, Rhee YS, Park ES Release kinetics of highly porous floating tablets containing cilostazol. Eur J Pharm Biopharm. 2017;115:39-51.

34. Raza A, Bukhari NI, Karim S, Hafiz MA, Hayat U. Floating tablets of minocycline hydrochloride: Formulation, in-vitro evaluation and optimization. Fut J Pharm Sci. 2017;3(2):131-9.

35. Varma M, Singla AK, Dhawan S. Release of diltiazem hydrochloride from hydrophilic matrices of polyethylene oxide and carbopol. Drug Dev Ind Pharm. 2004;30(5):545-53.

36. Saab M, Issa M, Samy W, Elmaradny HA. Intrinsically floating gastroretentive tablets of salbutamol sulphate using different sublimable/ release retarding materials: A comparative study. Int J Pharm Technol. 2015;7(1):8094-109.

37. Kalavathy MH, Regupathi I, Ganesa M, Miranda LR. Modelling, analysis and optimization of adsorption parameters for $\mathrm{H}_{3} \mathrm{PO}_{4}$ activated rubber wood sawdust using response surface methodology (RSM). Colloids Surf B Biointer. 2009;70:35-45.

38. Peng LX, Zou L, Zhao JL, Xiang DB, Zhu P, Zhao G. Response surface modeling and optimization of ultrasound-assisted extraction of three flavonoids from tartary buckwheat (Fagopyrum tataricum). Pharmacogn Mag. 2013;9(35):210-5.

39. Bai Y, Saren G, Huo W. Response surface methodology (RSM) in evaluation of the vitamin $\mathrm{C}$ concentrations in microwave treated milk. J Food Sci Technol. 2015;52(7):4647-51.

40. Mourabet M, El Rhilassi A, El Boujaady H, Bennani-Ziatni M, Taitai A. Use of response surface methodology for optimization of fluoride adsorption in an aqueous solution by Brushite. Arab J Chem. 2017;10:S3292-302.

41. Muthukumar M, Mohan D, Rajendran M. Optimization of mix proportions of mineral aggregates using Box Behnken design of experiments. Cem Concr Compos. 2003;25:751-8. 